\title{
Article \\ Surface Treatment of Ultra-High Molecular Weight Polyethylene (UHMWPE) by Cold Atmospheric Plasma (CAP) for Biocompatibility Enhancement
}

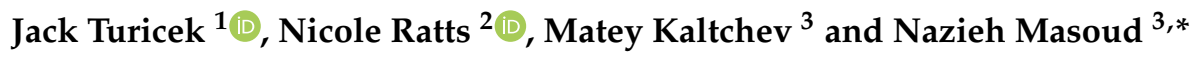 \\ 1 Department of Mechanical Engineering, Milwaukee School of Engineering, Milwaukee, WI 53202, USA; \\ turicekjs@msoe.edu \\ 2 Department of Electrical Engineering and Computer Science, Milwaukee School of Engineering, \\ Milwaukee, WI 53202, USA; rattsn@msoe.edu \\ 3 Department of Physics and Chemistry, Milwaukee School of Engineering, Milwaukee, WI 53202, USA; \\ kaltchev@msoe.edu \\ * Correspondence: masoud@msoe.edu
}

check for updates

Citation: Turicek, J.; Ratts, N.; Kaltchev, M.; Masoud, N. Surface Treatment of Ultra-High Molecular Weight Polyethylene (UHMWPE) by Cold Atmospheric Plasma (CAP) for Biocompatibility Enhancement. Appl. Sci. 2021, 11, 1703. https:// doi.org/10.3390/app11041703

Academic Editor: Vandana Miller Received: 7 January 2021

Accepted: 10 February 2021

Published: 14 February 2021

Publisher's Note: MDPI stays neutral with regard to jurisdictional clai$\mathrm{ms}$ in published maps and institutional affiliations.

Copyright: (C) 2021 by the authors. Licensee MDPI, Basel, Switzerland. This article is an open access article distributed under the terms and conditions of the Creative Commons Attribution (CC BY) license (https:// creativecommons.org/licenses/by/ $4.0 /)$.

\begin{abstract}
Ultra-high molecular weight polyethylene (UHMWPE) is one of the most commonly used polymers in joint replacements because of its biologically inert properties and low friction coefficient. However, it has downfalls relating to its wear, adhesion, and lubrication. In this study, UHMWPE samples were treated with a tubular helium cold atmospheric pressure (CAP) plasma source in order to improve three properties of the polymer: (1) its wear resistance, which was characterized by durometer hardness, (2) its lubrication characterized by water contact angle, and (3) its adhesion characterized by both root mean square surface roughness $\left(R_{q}\right)$ and water contact angle. The polymer was treated by two different parts of the plasma plume (the base and the tip) at two different helium flow rates $(1 \mathrm{~L} / \mathrm{min}$ and $2.5 \mathrm{~L} / \mathrm{min})$, for different treatment times. Results of the plasma treatment showed a decrease in the contact angle of between 32 and 54 degrees, a significant increase in the roughness by up to 10 times the pristine surface, and no substantial change in the hardness. These improvements to the adhesion and lubrication properties of the polymer examined suggest that the treated surface could be more suitable for use in artificial joints.
\end{abstract}

Keywords: cold atmospheric plasma; UHMWPE surface modification; biocompatibility

\section{Introduction}

A tubular cold atmospheric pressure plasma source was investigated and characterized by the authors in a previous study [1]. The plasma produced by this source was generated by flowing helium gas through a glass tube with a copper electrode rounded externally around it to provide an electric field for gas excitation. The plasma plume extended for up to a few centimeters from the opening of the tube as shown in Figure 1.

Optical Emission Spectroscopy (OES) was used to identify the composition of the plasma along the length of the plume. Results indicated that the type of the plasma species and the intensity of the species' emissions changed at different locations along the plume. Furthermore, spectra were taken for the plasma jet in both a free jet configuration and with an UHMWPE sample present in the plume. For the free jet configuration, one of the emissions measured was the $\mathrm{OH}$ line at $308 \mathrm{~nm}$, present only at the base of the plasma plume near the tube opening, while the rest of the plume was dominated by nitrogen Second Positive and First Negative systems. 


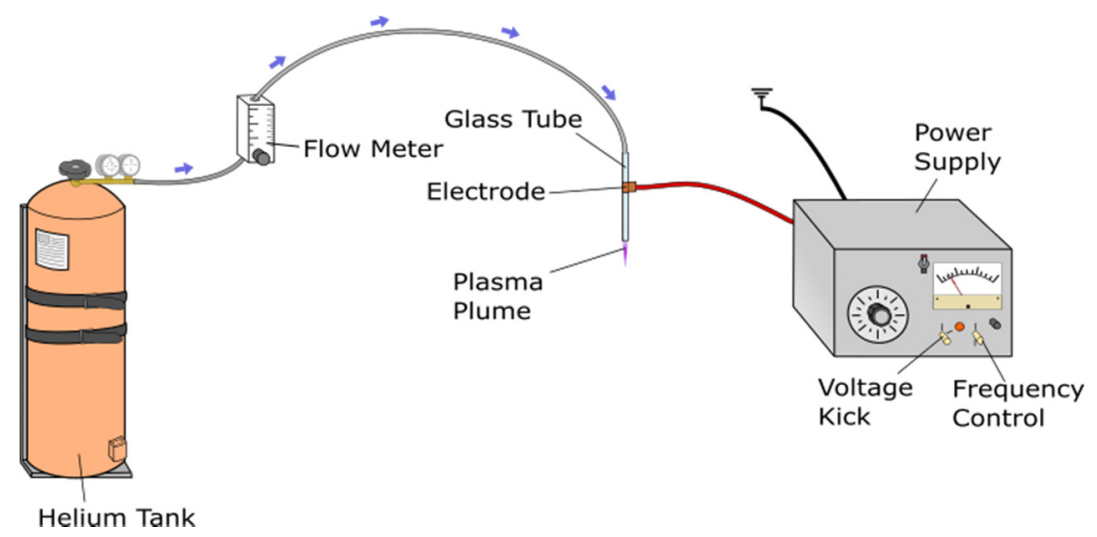

Figure 1. Schematic of cold atmospheric plasma (CAP) source used for the treatment of the UltraHigh-Molecular-Weight Polyethylene (UHMWPE) samples.

It was also found that the flow rate of the source gas played a role in the emission type and intensity of the plasma species. Higher flow rates led to higher intensities of $\mathrm{OH}$ at the base of the plasma plume. Additionally, the intensity of all emissions was found to decrease moving away from base of the plume and the opening of the source tube towards the tip. The $\mathrm{OH}$ emission was attributed to water condensation on the inner tube surfaces, while the $\mathrm{N}_{2}$ and $\mathrm{N}_{2}{ }^{+}$emissions came from the interaction between the plasma and the nitrogen of the ambient air. With the UHMWPE surface present in the plume, the emission spectra were similar to the free jet configuration with some increased intensity of the $\mathrm{OH}$ lines and a new He emission that was measured as the surface was moved closer to the base of the plasma plume. These changes were attributed to the obstruction that the UHMWPE sample provided between the plasma and the ambient air. The results obtained from the previous study can be summarized in the spectra shown in Figure 2.

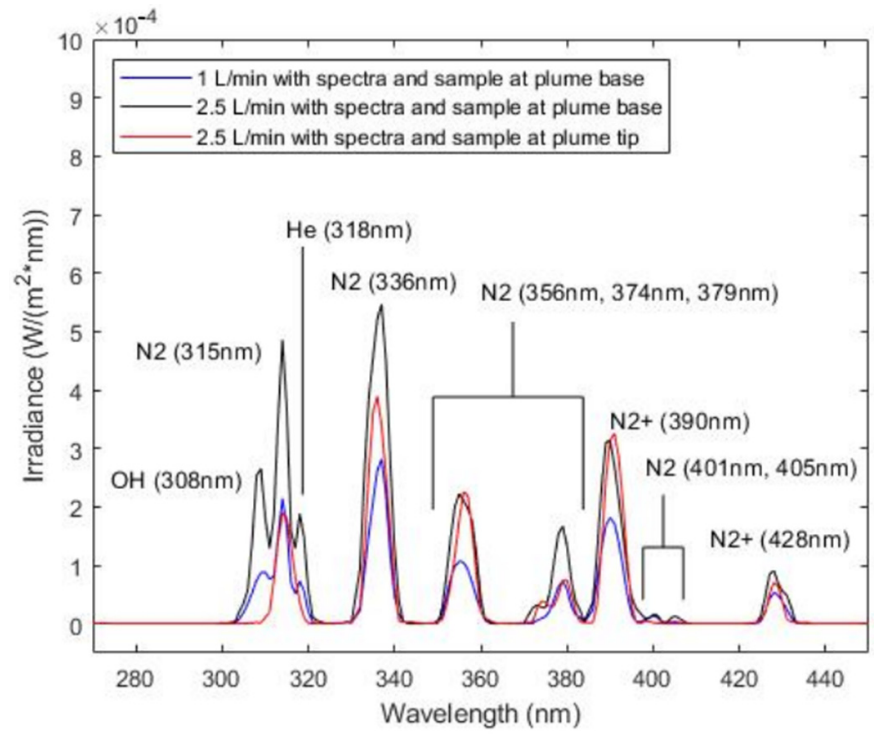

Figure 2. Optical Emission Spectroscopy (OES) spectra of the plasma plume with the UHMWPE sample present at its treatment locations and with its treatment flow rates.

The presence of the $\mathrm{OH}$ and nitrogen plasma species provides a unique application of the CAP plasma source in the modification of polymeric surfaces. This modification occurs when the species of the plasma interact both mechanically and chemically to change the surface properties of the polymer, such as its morphology and the functional groups present, without affecting the bulk material.

A use case where polymer surface modification can be important is for the pretreatment of UHMWPE to be incorporated in joint implants. UHMWPE is a semi crystalline 
polymer whose crystalline and amorphous phases both influence its mechanical properties [2,3]. It is part of the polyethylene (PE) family of polymers and has a repeating unit of $\left(\mathrm{C}_{2} \mathrm{H}_{4}\right)_{n}$ in a linear configuration [2]. This polymer is often used in joint replacements in the knee and hip because of its biocompatibility, low friction coefficient, biological inertness, and inexpensive cost [2,4-6]. With the numerous beneficial properties of UHMWPE, it makes this biopolymer a highly sought-after product. UHMWPE has been the material of choice when it comes to many biomedical applications. Not only has UHMWPE's demand in the market raised from 60.9 kilotons to 204.8 kilotons during 2015-2024, its value also stands at about $\$ 1.36$ billion [7]. With this increase in demand, UHMWPE has an annual compounded growth rate of about 15\% [7]. Furthermore, there have been many studies to further improve upon UHMWPE for its use in biomedical applications. For example, advances in this material have been investigated by modifying the surface of the polymer with electron beam, CAP plasma in the ambient air, and with carbon ion immersion [7]. Additionally, experiments have been performed to improve both the surface as well as the bulk properties of UHMWPE by reinforcing the polymer matrix with various composite materials [7]. All of these advances can be referenced in more detail in Patil et al. [7]. Along with increased research in improving the polymer properties, there have also been studies concerning characterizing the mechanical failure of UHMWPE in applications such as the laser welding of lap joints investigated in $[8,9]$.

Yet, it has been shown that there are shortcomings associated with implementing UHMWPE as well, as it is still in many cases a major factor contributing to the failure of joint replacements [2]. The first downside of UHMWPE is that it does not have very good wear characteristics $[4,10]$. When a joint is in use over time, small particles of the polymer wear off into the surrounding tissue, which can eventually cause failure of joint replacement because the wear debris can trigger a response by the immune system, causing the implant to loosen $[2,5,10,11]$. When it loosens too much, it can cause pain and may create a necessity for the joint to be replaced again. Another related issue is the adhesion of UHMWPE to the bone and lubrication by the synovial fluid in the joint $[4,10,12]$. These issues result because of the polymer's inertness and nonpolar properties [12]. Furthermore, the low compatibility of the UHMWPE surface to the synovial fluid in the joint causes an inability of the fluid to cover the polymer [10]. The negative effects of the low wettability of the surface outweigh the positive effects of the low friction coefficient of UHMWPE and can cause more wear [10]. Improvement of the wettability by making the surface more hydrophilic can increase the lubrication in the joint and therefore decrease the wear of the polymer [10]. The increased wettability as well as increased roughness can also positively affect the adhesion of the polymer surface to the adjacent bone, further improving the performance of the joint replacement [6,12].

Due to the suboptimal wear, adhesion, and lubrication properties of UHMWPE, the goal of this study was to investigate the effects of a helium tubular CAP plasma treatment for the improvement of the hardness of the surface of the polymer to characterize its mechanical wear, and the surface roughness and contact angle to characterize the adhesion and lubrication properties. Many other studies have used plasma to modify the surface of UHMWPE or other polymers for this desired purpose. It is widely accepted that plasma treatment decreases the contact angle on the surface of a polymer, thereby increasing its hydrophilicity $[4,12,13]$. For roughness on the other hand, there seems to be some discrepancy on the ability of different plasma sources to have a sizable effect as Vrekhem et al. [12] reported no significant change in the root mean square roughness of the surface with its argon CAP source, while references $[13,14]$ showed significant increase in the $R_{q}$ value of the surface after plasma treatment with their respective oxygen and nitrogen sources. Furthermore, in the aforementioned previous study, Turicek et al. found that both the location in the plasma plume used for treatment and the helium source flow rate had different magnitudes of effects on the roughness of UHMWPE samples that were preliminarily treated. This discovery added to the motivation for this study to correlate 
the type and intensity of plasma species to the chemical and physical changes of the treated surface.

The effects of the length of time of the plasma treatment, the part of the plasma plume used for treatment, and the flow rate of the helium gas on the surface properties of UHMWPE were studied. The polymer properties analyzed throughout the plasma treatment included the durometer hardness, water contact angle, and root mean square roughness to determine if, and to what degree, the CAP treatment changed the surface of the polymer.

\section{Materials and Methods}

The UHMWPE samples used in this study had a molecular weight range of $5.2 \times 10^{6} \mathrm{~g} / \mathrm{mol}$ to $6.2 \times 10^{6} \mathrm{~g} / \mathrm{mol}$ as obtained from Mitsubishi Chemical Advanced Materials Inc. The UHMWPE resin used to make the purchased polymer sheet was manufactured in accordance with ASTM D4020. Other material properties of this polymer can be found in the data sheet in reference [15]. Thirteen-mm diameter circular samples with a 3-mm thickness were cut from the polymer sheet. The samples were then attached with epoxy to metal disks, which were needed later for compatibility with the atomic force microscope (AFM) machinery. These metal disks were then fixed to the top of 32-mm diameter epoxy pucks sized to fit into the polishing machine so that the samples could all be polished simultaneously with an automatic polisher. This setup is clarified in Figure 3.

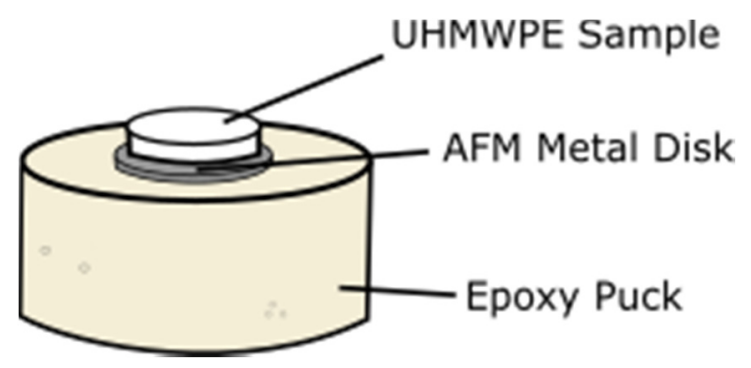

Figure 3. UHMWPE sample setup used for surface polishing and cleaning preparation.

A Buehler AutoMet Variable Speed Grinder Polisher was used with grit paper and diamond suspensions to polish the polymer samples down to a $0.05 \mu \mathrm{m}$ diamond suspension. After each of the samples was sufficiently polished, each was separated from the epoxy pucks and the bottom of the metal disk was sanded to remove excess epoxy and ensure they could be properly inserted into the AFM. The samples then underwent an additional cleaning treatment in a CD-4800 Ultrasonic Cleanser. This allowed the samples to be pristine enough to be analyzed by the AFM without risk of causing damage to the machine.

The CAP plasma source that was used for the various plasma treatments is shown in Figure 1. The source consists of a $4 \mathrm{~mm}$ inner diameter glass tube with a thickness of $1 \mathrm{~mm}$ and an $\mathrm{AC}$ voltage provided through a copper electrode rounded externally on the tube to excite the helium atoms and generate the plasma inside the tube. The generated plasma filled the entirety of the glass tube with its plume extending outside the tubing up to a few centimeters depending on the gas flow rate. The plasma was created with an AC voltage of about $15 \mathrm{kV}$ peak to peak, an RMS current of about $0.5 \mathrm{~A}$, and a frequency of $20 \mathrm{kHz}$ supplied to the electrode, which was placed $11.4 \mathrm{~cm}$ from the opening of the glass tube.

The samples were treated with different regions of the plasma plume, at different gas flow rates, and for different treatment times. Figure 4 shows a schematic of the two treatment locations of the UHMWPE samples used in this study, one at the tip of the plume and the other at the base of the plume near the opening of the tube. It is important to reference again that spectra were taken of the plasma plume with the UHMWPE sample present at these locations in the previous study by the authors and are presented in Figure 2. 
Tip

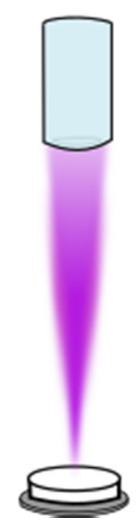

Figure 4. Tip and base treatment locations of the UHMWPE samples in the plasma plume.

The various source parameters used for treatment are summarized in Table 1 . The table also shows the measurements performed for each sample after each treatment.

Table 1. Summary of the measurements performed on the UHMWPE surface after the different plasma treatments.

\begin{tabular}{ccc}
\hline Flow Rate [L/min] & Position on Plume & Measurements Performed \\
\hline 1 & Base & $\begin{array}{c}\text { AFM, Contact Angle } \\
\text { Hardness }\end{array}$ \\
\hline 2.5 & Base & $\begin{array}{c}\text { AFM, Contact Angle } \\
\text { Hardness } \\
\text { AFM, Contact Angle } \\
\text { Hardness }\end{array}$ \\
\hline
\end{tabular}

The contact angle on each sample was measured after each plasma treatment to help characterize the wettability and adhesion properties of the polymer surface. Higher wettability and hydrophilic properties are related to better adhesion to the UHMWPE surface and a decrease in the wear on the polymer because of the increased lubrication, which stems from the improved interaction with the synovial fluid in the joint [10]. A decrease in the contact angle is an indication of an increase in the hydrophilicity of the surface $[6,16]$. To perform the contact angle measurements, a $0.5 \mu \mathrm{L}$ drop of deionized water was gently placed onto the UHMWPE samples using a Fisherbrand Finnpipette II micropipette, rated between 0.5 and $10 \mu \mathrm{L}$ and imaged using a digital camera. The image was then analyzed with Image (Wayne Rasband. Image J. version 1.52a; National Institutes of Health: USA, 2018.), which is a common software used for contact angle measurements [17]. The contact angle measurements were performed on the pristine samples as well as after each subsequent plasma treatment. A representative example of a water droplet on an UHMWPE sample is shown in Figure 5.

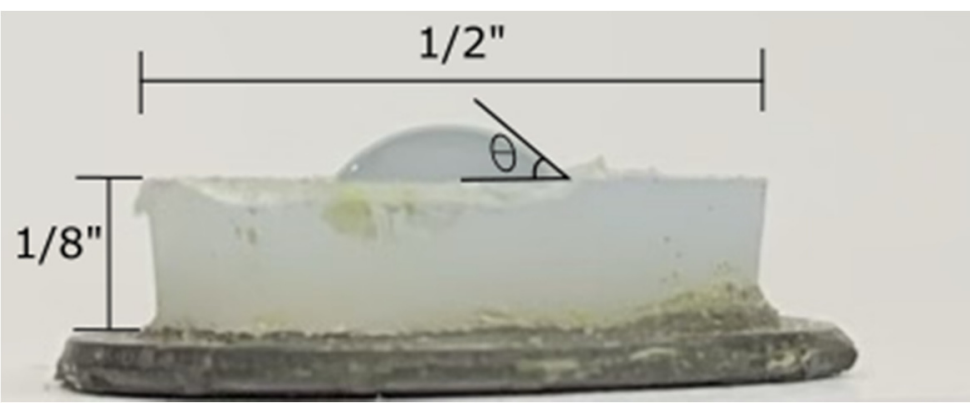

Figure 5. Representative contact angle measurement of the sample treated at the base position with a $1 \mathrm{~L} / \mathrm{min}$ flow rate. 
The roughness of the polymer surface was measured from images acquired with a Bruker Multimode atomic force microscope with a NanoScope IIIa controller operating in contact mode. For each sample, a $10 \mu \mathrm{m} \times 10 \mu \mathrm{m}$ area was scanned using a cantilever with a low force constant of $0.02 \mathrm{Nm}^{-1}$. The force exerted on the surface was maintained constant for all measurements. The images were further analyzed for roughness using the built-in tool of the Bruker NanoScope Analysis (NanoScope Analysis (32 bit), version 1.50 (Build B72.115792); Bruker Corporation: 2015.). To estimate the roughness, the rootmean-square average of the height deviations referenced to the mean sample plane were determined. For each sample image, three $2 \mu \mathrm{m} \times 2 \mu \mathrm{m}$ squares with uniform surface complexation were arithmetically averaged and the $R_{q}$ value recorded. This was done to ensure measurement error singularities from the AFM were not included in the reported value. The roughness has shown to be a factor that increases the adhesion properties of the polymer [6]. However, a rougher surface could also cause more wear, furthering the importance that it be monitored throughout the treatment process. An AFM measurement was first taken preliminarily on each sample and then again after each plasma treatment for each sample.

Because the wear resistance of a surface is difficult to measure directly, the hardness was used to characterize the mechanical wear. Many studies related an increase in both hardness and wear resistance to the increased crosslinking of the polymer surface $[10,14,18]$. Moreover, it has been shown that other plasma sources were effective at improving wear properties because of their ability to crosslink the surface [19]. To perform the hardness measurement, a Rex Shore-D durometer was pressed into the sample. The initial maximum hardness value was recorded, and the durometer was held in place for an additional $15 \mathrm{~s}$, after which this value was recorded. This was in accordance with the instructions for the 1600 model. Further information on these instructions can be found in reference [20].

\section{Results and Discussion}

\subsection{Contact Angle}

The contact angle measurements of the treated samples are shown in Figure 6.

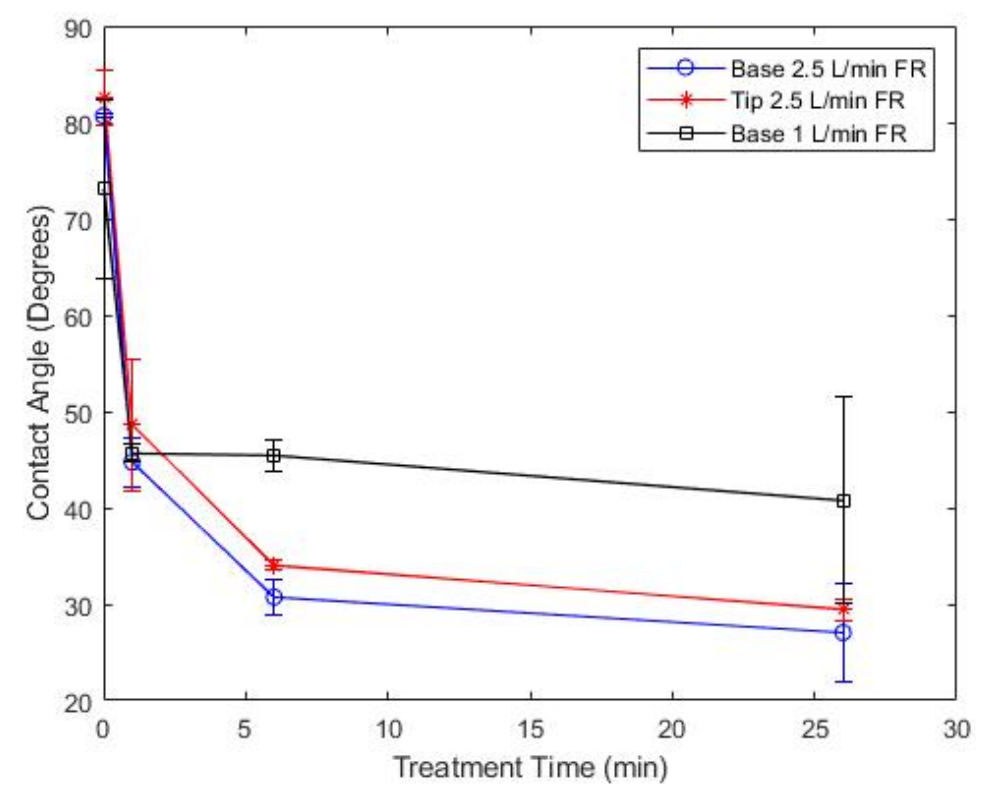

Figure 6. Contact angle measurements analyzed by ImageJ (Wayne Rasband. Image J. version 1.52a; National Institutes of Health: USA, 2018.).

Figure 6 shows that the contact angle significantly decreased with plasma treatment time seeming to follow a somewhat exponential decay. This was a favorable result, as it is of benefit for the wettability of biopolymers to be hydrophilic due to the positive 
effects relating to protein adsorption, the adhesion of cells in the body, and the increase of lubrication within joints $[6,10]$. The initial contact angle measurements had a mean value of $79^{\circ}$ with a standard deviation of only $5^{\circ}$ supporting the repeatability of the measurements and the polishing process as the pristine polymer contact angles should have all been the same. With sequential treatments the contact angle decreased, the most dramatic changes generally occurring in the first minute of treatment. The change in the contact angle can be attributed to a two-phase process, first starting with the creation of free radicals on the polymer surface, then finishing with the interactions of certain species with the radicals producing changes to the properties of the surface [6]. The presence of oxygen and $\mathrm{OH}$ species for these interactions have shown to create a more hydrophilic behavior on the polymer in other studies [6,21]. Furthermore, the $\mathrm{OH}$ species were shown to be most abundant at the base position of the plasma plume as the helium flow was increased, as shown in Figure 2, which displays spectra taken of the plasma plume with the UHMWPE sample present at its respective treatment locations and for the two different flow rates. It can be clearly seen that the higher flow rate with the sample at the base of the plasma plume produced the highest intensity $\mathrm{OH}$ emission at $308 \mathrm{~nm}$, thereby supporting why such a dramatic decrease in the contact angle occurred under these treatment conditions.

When interacting with the free radicals on the polymer surface, the oxygen species form polar groups such as hydroxyl and carbonyl functional groups [6,12]. The surface then exhibits a more hydrophilic behavior as the newly integrated polar species in the polymer surface interact with the polar water droplet. The contact angle of the sample treated by the base part of the plasma plume with the higher $2.5 \mathrm{~L} / \mathrm{min}$ flow rate after the 20-min treatment was measured at $27^{\circ}$, which is $54^{\circ}$ lower than the $81^{\circ}$ angle obtained without the plasma treatment.

There seems to be some debate on the influence of nitrogen species, which was found to be more dominant in the middle and lower parts of the plasma plume, on the polymer surface wettability. Gott et al. [22] stated that $\mathrm{N}_{2}$ and other nitrogen species can cause peptide coupling which could lead to a decrease in wettability. However, most studies liken the effect of nitrogen species with that of oxygen because they too provide polar groups on the polymer surface, increasing the hydrophilic behavior $[4,23]$. This latter argument supports what was found in this study; when the sample was treated by the nitrogen dominated tip of the plasma plume, with a flow rate of $2.5 \mathrm{~L} / \mathrm{min}$, the sample showed a decrease in the contact angle from $83^{\circ}$ on the untreated sample to $29^{\circ}$ on the treated sample after the 20-min plasma treatment. This is a decrease of $53^{\circ}$, which is only slightly less than the $54^{\circ}$ found for the contact angle at the base position and can perhaps be attributed to a very slight effect of the $\mathrm{OH}$ and oxygen species on the contact angle of a polymer surface when compared to that of just the nitrogen species.

At the lower flow rate of $1 \mathrm{~L} / \mathrm{min}$ at the base position, the change in contact angle was only $32^{\circ}$ after the 20 -min treatment. This is a smaller decrease in the contact angle when compared to those of the treatments with higher flow rates, which leads to the conclusion that the gas flow rate had a larger effect on the contact angle than the part of the plasma plume used for treatment. This effect can be clearly seen in Figure 6. The smaller decrease in contact angle may relate to the very miniscule amount of $\mathrm{OH}$ formed at the $1 \mathrm{~L} / \mathrm{min}$ flow rate at the base position because, again, as the flow rate increased, so did the intensity of $\mathrm{OH}$ emissions at the base location, as shown in Figure 2. This, then, may have contributed to a decrease in the number of polar groups being integrated into the polymer surface at the lower flow rate. In similar studies, after $30 \mathrm{~min}$ of plasma treatment, no significant change in the contact angle was measured, which was supported by the data in this paper with the leveling off of the contact angle values [13].

\subsection{Roughness}

Figure 7 shows the roughness measurements obtained by the AFM, where the root mean square values measured after the surface treatments are plotted against the treatment time. 


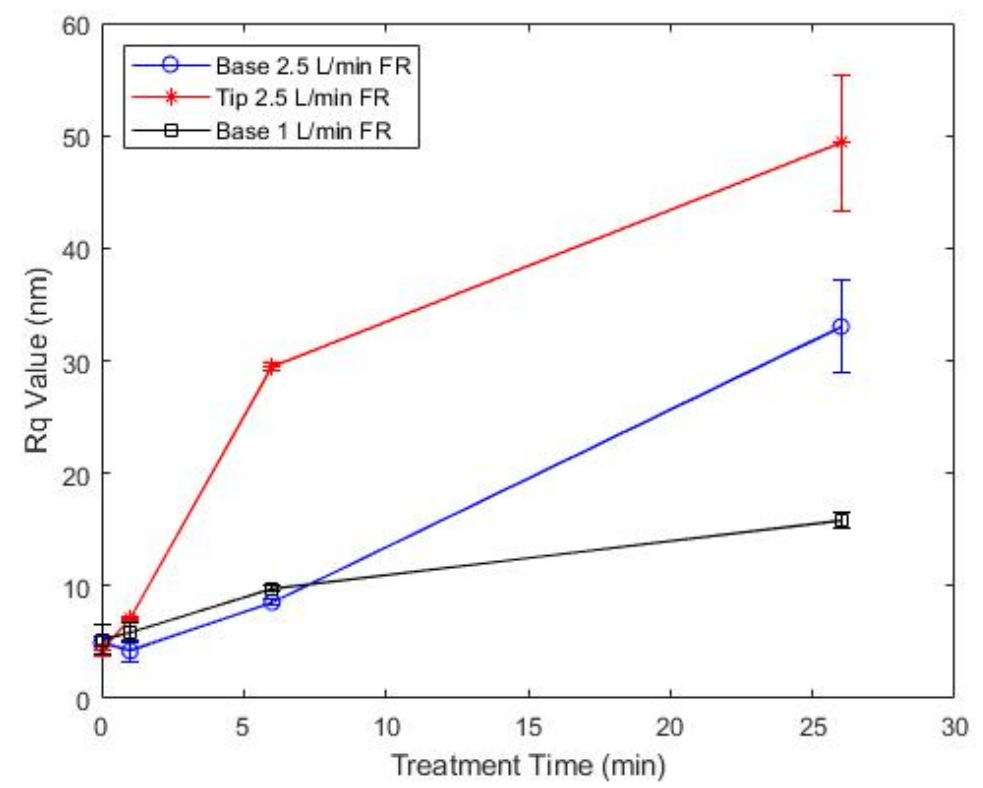

Figure 7. Rq roughness measurements measured by AFM and analyzed by NanoScope Analysis (NanoScope Analysis (32 bit), version 1.50 (Build B72.115792); Bruker Corporation: 2015.).

To characterize the pristine surface, the measured Rq roughness values for all the samples were arithmetically averaged to be $4.83 \mathrm{~nm}$, with a standard deviation of $0.84 \mathrm{~nm}$. Figure 7 shows that roughness increased with treatment time. This increase in roughness was common among all the treatment conditions, and the trend is supported in other studies [13]. The treatment conditions did, however, influence the magnitude of change in surface roughness. For example, the sample treated at the plume's base at the lowest flow rate of $1 \mathrm{~L} / \mathrm{min}$ had the lowest increase in roughness, namely, of only slightly greater than three times the pristine value. This is much smaller than the nearly seven times and over 10 times increase measured for the samples treated at the plume's base and tip, respectively, at the higher $2.5 \mathrm{~L} / \mathrm{min}$ flow rate.

To accompany the roughness data, AFM images have been included in Figure 8 to show the progression of the surface of the polymer with successive plasma treatments. All the images in Figure 8 are $5 \mu \mathrm{m} \times 5 \mu \mathrm{m}$ scans of the sample treated at the base position with a flow rate of $2.5 \mathrm{~L} / \mathrm{min}$.

Figure 8a shows a uniform surface with few irregularities. The fine directional scratches on the surface are from the polishing process. Figure $8 \mathrm{~b}$ shows a slight increase in the number of irregularities, as a few started to appear throughout the scan, though this increase was not very substantial when compared to that of further treatment times. This was significant because after the 1-min treatment, the roughness was hardly changed, while there was a substantial increase in the wettability of the surface. As the treatment progressed, a substantial visual difference began to occur after the 5-min treatment, as can be seen in Figure 8c, with small inhomogeneities appearing more often throughout the scan. These inhomogeneities further intensified after the 20-min treatment, as shown in Figure 8d. 

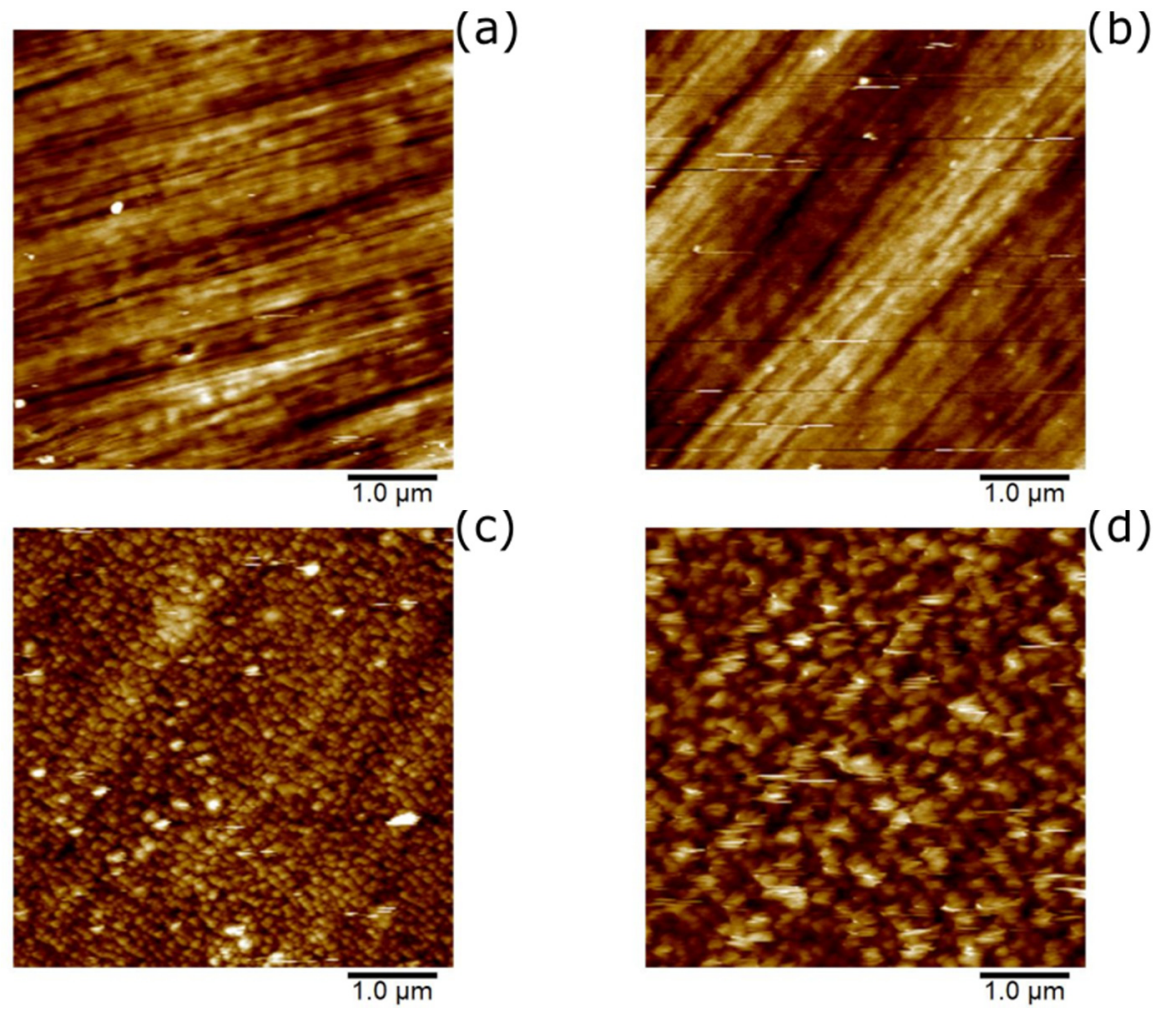

Figure 8. AFM images (a) before plasma treatment, (b) after the 1-min treatment, (c) after the 5-min treatment, and (d) after the 20-min treatment at the base plume position with a $2.5 \mathrm{~L} / \mathrm{min}$ flow rate taken with NanoScope Analysis (NanoScope Analysis (32 bit), version 1.50 (Build B72.115792); Bruker Corporation: 2015.).

The increase in roughness with plasma treatment was caused by the bombardment of the surface of the polymer with the plasma species and the scission of the UHMWPE polymer chains $[13,24]$. Additionally, the sporadic nature of the inhomogeneities found with the AFM images shows the uneven nature of the plasma treatment [13]. The circular divots on the surface of the polymer can be explained further in depth with an investigation of the sputtering effects of the plasma at the polymer surface, which was also seen in reference [13] with a plasma treatment on the polycarbonate. The sputtering of a polymer surface happens when particles with sufficient energy collide with the surface and detach small pieces or atoms $[25,26]$. The reason that material is removed is that, after polymer chain scission, the free radicals formed recombine into new lower molecular weight species and because the oxidation that takes place on the surface, the particles become more fragile and it is easier for pieces to be removed $[4,13]$. Another surface effect that plasma treatment could cause, besides the creation and removal of lower molecular weighted species, is the forming of higher molecular weight species by crosslinking [13]. This second process, however, was probably not observed much in this study because of the negligible change in hardness, as discussed later. Because the sputtering process requires a certain amount of energy to remove pieces of the surface, it makes sense that with the lower flow rate, and therefore, a smaller amount of kinetic energy, that not as much of this sputter effect would have occurred. This explains the lower magnitude of increase in the surface roughness of the sample treated with the lower $1 \mathrm{~L} / \mathrm{min}$ flow rate. There does not seem to be many publications that described why the roughness from the treatment of the sample at the tip of the plasma plume increased more than the treatment of the sample at the same flow rate but at the base position. However, this could be related to the He and $\mathrm{OH}$ present at the base position, as this was one of the only major differences between the spectra taken at the base and tip positions. However, further investigation would need to be performed to determine why this outcome occurred more definitively. 


\subsection{Hardness}

The hardness measurements are shown in Tables 2 and 3. The initial maximum hardness measurements were taken immediately after the durometer was pressed to the polymer and are shown in Table 2. These measurements were considered the 'peak' values, as the maximum value was reached right after the durometer was secured in place.

Table 2. Maximum hardness readings.

\begin{tabular}{cccc}
\hline \multirow{2}{*}{ Treatment Time (min) } & Base FR:1 L/min & $\begin{array}{c}\text { Hardness (Shore-D) [duro] } \\
\text { Base FR: 2.5 L/min }\end{array}$ & Tip FR: 2.5 L/min \\
\hline 0 & 68.7 & 68.7 & 68.7 \\
1 & 70.5 & 69 & 70 \\
6 & 70.5 & 70 & 70 \\
26 & 70.5 & 69 & 69 \\
\hline
\end{tabular}

Table 3. Hardness measurements after $15 \mathrm{~s}$ of depression.

\begin{tabular}{cccc}
\hline \multirow{2}{*}{ Treatment Time (min) } & Base FR:1 L/min & $\begin{array}{c}\text { Hardness (Shore-D) [duro] } \\
\text { Base FR: } \mathbf{2 . 5} \text { L/min }\end{array}$ & Tip FR: $\mathbf{2 . 5}$ L/min \\
\hline 0 & 64.7 & 64.7 & 64.7 \\
1 & 67 & 64 & 65 \\
6 & 67.5 & 65 & 66 \\
26 & 67 & 65 & 67 \\
\hline
\end{tabular}

As the durometer was held in place, the needle on the tip of the durometer began to penetrate through more of the surface of the plastic. Given this, another hardness value was then recorded after $15 \mathrm{~s}$ of holding the durometer in place. The measured hardness values after the durometer were held into the polymer for $15 \mathrm{~s}$, as can be seen in Table 3 .

There was no significant change to the maximum hardness values. However, there did appear to be some small increase in the $15 \mathrm{~s}$ depression values. Modifying and improving the hardness of polymers has been shown to be possible with some plasma sources $[14,19,27]$. The increase in hardness is related to the amount of crosslinking of the polymer chains at the surface [14]. This crosslinking comes when the free radicals on different polymer chains interact and combine [14]. As was discovered from the increase in the hydrophilicity and roughness, there were likely some free radicals that were created on the polymer surface, and thus, the treatment may have created a small amount of crosslinking that could account for the small changes in the hardness values, as shown in Tables 2 and 3.

To summarize the results of CAP plasma treatment on the surface of the UHMWPE polymer, it was found that there were significant increases in both the hydrophilicity and roughness with increasing treatment time, specifically at the higher $2.5 \mathrm{~L} / \mathrm{min}$ flow rate. This trend has positive effects when incorporating a polymer into a joint replacement. First, the increase in the hydrophilicity of the polymer leads to a better interaction with the synovial fluid in a joint and to increased adhesion to the bone [10,12]. Secondly, the increase in surface roughness could lead to better adhesion because of the increase in the surface area of the polymer $[6,28,29]$. Finally, although there was no measurable change in the surface hardness to relate to an increase in wear resistance, the increased lubrication and adhesion from the improvement of the other surface properties did lead to a material with a more biocompatible surface. However, one point of caution that should be noted is that there are both advantages and disadvantages to increasing the surface roughness. For example, although a rougher surface does lead to better adhesion and there is less chance of the implant loosening from a surface area perspective, it could also lead to more wear of small particles off of the polymer surface, causing negative long-term effects in the joint $[10,29]$. This could perhaps be avoided by treating the polymer for lower treatment times, given that, for the UHMWPE examined, after just a 1-min treatment time, the 
samples showed a significant decrease in the contact angle without significantly affecting the roughness. A short plasma treatment could, therefore, allow for the taking advantage of the increased lubrication involved in the joint corresponding to the decrease in the contact angle without the disadvantage of the possible increased wear from an increase in the surface roughness [4].

\section{Conclusions}

UHMWPE samples were treated with a tubular atmospheric plasma source fed with helium gas. The decreases in the contact angle from periodic measurements point to a more hydrophilic surface, with the largest measured decreases taking place on the polymer treated at the base and the tip of the plasma plume at the higher flow rate. The roughness, measured by the AFM, showed an increase of up to 10 times when the polymer was treated with the tip of the plasma plume at a flow rate of $2.5 \mathrm{~L} / \mathrm{min}$. The increase in both the hydrophilicity and roughness suggests better adhesion characteristics of the polymer as well as a potential increase in lubrication with the improved interaction with the synovial fluid in a joint. Shorter treatment times showed a substantial decrease in the contact angle with a miniscule increase in the roughness and could, therefore, be used to better lubrication without increasing roughness related wear. The hardness, and hence, the mechanical wear resistance, conversely, did not show a substantial change with the plasma treatments. However, because of the increased lubrication and adhesion demonstrated by the decrease in the contact angle and increase in the surface roughness, the results show that the UHMWPE polymer treated by the helium tubular CAP source in this paper could offer benefits over its untreated counterparts, relating to its application in joint replacements.

Author Contributions: J.T. and N.R. contributed with the acquisition and preparation of the UHMWPE samples, the performing of the different plasma treatments, and the contact angle and hardness measurements. M.K. attained the AFM roughness measurements and gave advice on their interpretation. N.M. gave guidance throughout the entirety of the research from the conceptualization through the physical testing phases, as well as secured the equipment for the plasma source. The manuscript was primarily written by J.T. and N.R. and reviewed and edited by N.M. and M.K. All authors have read and agreed to the published version of the manuscript.

Funding: This research received no external funding.

Institutional Review Board Statement: Not applicable.

Informed Consent Statement: Not applicable.

Data Availability Statement: None.

Acknowledgments: The plasma source was developed with the support of a Milwaukee School of Engineering summer professional development grant. The authors would like to acknowledge the help of Kevin Hart for his assistance in polishing the polymer samples before the plasma treatment.

Conflicts of Interest: The authors declare no conflict of interest.

\section{References}

1. Turicek, J.; Ratts, N.; Kaltchev, M.; Masoud, N. Characterization of Helium CAP Tubular Source and Investigation of UHMWPE Surface Treatment. In Proceedings of the 73rd Annual Gaseous Electronics Virtual Conference, Princeton, NJ, USA, 5-9 October 2020.

2. Sobieraj, M.; Rimnac, C. Ultra High Molecular Weight Polyethylene: Mechanics, Morphology, and Clinical Behavior. J. Mech. Behav. Biomed. Mater. 2009, 2, 433-443. [CrossRef] [PubMed]

3. Bracco, P.; Bellare, A.; Bistolfi, A.; Affatato, S. Ultra-High Molecular Weight Polyethylene: Influence of the Chemical, Physical and Mechanical Properties on the Wear Behavior. A Review. Materials 2017, 10, 791. [CrossRef]

4. Preedy, E.C.; Brousseau, E.; Evans, S.L.; Perni, S.; Prokopovich, P. Adhesive forces and surface properties of cold gas plasma treated UHMWPE. Colloids Surf. A Physicochem. Eng. Asp. 2014, 460, 83-89. [CrossRef]

5. Anonymous. Meeting the Joint Replacement Challenge with UHMWPE. MDDI Online, 1 March 2005. Available online: https:/ / www.mddionline.com/meeting-joint-replacement-challenge-uhmwpe(accessed on 24 April 2020).

6. Bykova, I.; Weinhardt, V.; Kashkarova, A.; Lebedev, S.; Baumbach, T.; Pichugin, V.; Zaitsev, K.; Khlusov, I. Physical properties and biocompatibility of UHMWPE-derived materials modified by synchrotron radiation. J. Mater. Sci. Mater. Med. 2014, 25, 1843-1852. [CrossRef] [PubMed] 
7. Patil, N.A.; Njuguna, J.; Kandasubramanian, B. UHMWPE for biomedical applications: Performance and functionalization. Eur. Polym. J. 2020, 125, 109529. [CrossRef]

8. Visco, A.; Scolaro, C.; Terracciano, T.; Montanini, R.; Quattrocchi, A.; Torrisi, L.; Restuccia, N. Static and dynamic characterization of biomedical polyethylene laser welding using biocompatible nano-particles. EPJ Web Conf. 2018, 167, 05009. [CrossRef]

9. Visco, A.; Scolaro, C.; Quattrocchi, A.; Montanini, R. Response to fatigue stress of biomedical grade polyethylene joints welded by a diode laser. J. Mech. Behav. Biomed. Mater. 2018, 86, 390-396. [CrossRef]

10. Baena, J.C.; Wu, J.; Peng, Z. Wear Performance of UHMWPE and Reinforced UHMWPE Composites in Arthroplasty Applications: A Review. Lubricants 2015, 3, 413-436. [CrossRef]

11. Marcondes, A.R.; Ueda, M.; Kostov, K.G.; Beloto, A.F.; Leite, N.F.; Gomes, G.F.; Lepienski, C.M. Improvements of ultra-high molecular weight polyethylene mechanical properties by nitrogen plasma immersion ion implantation. Braz. J. Phys. 2004, 34, 1667-1672. [CrossRef]

12. Van Vrekhem, S.; Vloebergh, K.; Asadian, M.; Vercruysse, C.; Declercq, H.; Van Tongel, A.; de Wilde, L.; de Geyter, N.; Morent, R. Improving the surface properties of an UHMWPE shoulder implant with an atmospheric pressure plasma jet. Sci. Rep. 2018, 8, 4720. [CrossRef]

13. Nair, K.; Whiteside, B.; Grant, C.; Patel, R.; Tuinea-Bobe, C.; Norris, K.; Paradkar, A. Investigation of Plasma Treatment on Micro-Injection Moulded Microneedle for Drug Delivery. Pharmaceutics 2015, 7, 471-485. [CrossRef]

14. Qureshi, A.; Shah, S.; Pelagade, S.; Singh, N.L.; Mukherjee, S.; Tripathi, A.; Despande, U.P.; Shripathi, T. Surface modification of polycarbonate by plasma treatment. J. Phys. Conf. Ser. 2010, 208, 012108. [CrossRef]

15. Mitsubishi Chemical Advanced Materials TIVAR®1000 UHMW-PE, (Natural \& Colors except Black) UHMW-PE (ASTM Product Data Sheet). Available online: http:/ / qepp.matweb.com/search/DataSheet.aspx?Bassnum=P1SMP00\&ckck=1 (accessed on 10 June 2020).

16. Al-Malik, H.L.R. Adhesive and Tribological Behaviour of Cold Atmospheric Plasma-Treated Polymer Surfaces. Ph.D. Thesis, Szent Istvan University, Budapest, Hungary, 2018; p. 115.

17. Schuster, J.M.; Schvezov, C.E.; Rosenberger, M.R. Influence of Experimental Variables on the Measure of Contact Angle in Metals Using the Sessile Drop Method. Procedia Mater. Sci. 2015, 8, 742-751. [CrossRef]

18. Affatato, S.; Ruggiero, A.; Merola, M. Advanced biomaterials in hip joint arthroplasty. A review on polymer and ceramics composites as alternative bearings. Compos. Part B Eng. 2015, 83, 276-283. [CrossRef]

19. Kumar, N.N.; Yap, S.L.; Bt Samsudin, F.N.D.; Khan, M.Z.; Pattela Srinivasa, R.S. Effect of Argon Plasma Treatment on Tribological Properties of UHMWPE/MWCNT Nanocomposites. Polymers 2016, 8, 295. [CrossRef]

20. Rex Gauge Company, Inc. Operating Instructions. Available online: https://www.durometer.com/wp-content/uploads/ REXOpInstrucv1214r.pdf (accessed on 24 April 2020).

21. Nikiforov, A.Y.; Sarani, A.; Leys, C. The influence of water vapor content on electrical and spectral properties of an atmospheric pressure plasma jet. Plasma Sources Sci. Technol. 2011, 20, 015014. [CrossRef]

22. Gott, R.P.; Xu, K.G. OH Production and Jet Length of an Atmospheric-Pressure Plasma Jet for Soft and Biomaterial Treatment. IEEE Trans. Plasma Sci. 2019, 47, 4988-4999. [CrossRef]

23. Kasalkova, N.S.; Slepicka, P.; Kolska, Z.; Svorcik, V. Wettability and Other Surface Properties of Modified Polymers. Wetting Wettability 2015, 12, 323-356. [CrossRef]

24. Mandolfino, C.; Lertora, E.; Gambaro, C. Effect of Cold Plasma Treatment on Surface Roughness and Bonding Strength of Polymeric Substrates. Key Eng. Mater. 2014. [CrossRef]

25. Macgregor, M.; Vasilev, K. Perspective on Plasma Polymers for Applied Biomaterials Nanoengineering and the Recent Rise of Oxazolines. Materials 2019, 12, 191. [CrossRef] [PubMed]

26. Puliyalil, H.; Cvelbar, U. Selective Plasma Etching of Polymeric Substrates for Advanced Applications. Nanomaterials 2016, 6, 108. [CrossRef] [PubMed]

27. Ohkubo, Y.; Shibahara, M.; Nagatani, A.; Honda, K.; Endo, K.; Yamamura, K. Comparison between adhesion properties of adhesive bonding and adhesive-free adhesion for heat-assisted plasma-treated polytetrafluoroethylene (PTFE). J. Adhes. 2018, 96, 776-796. [CrossRef]

28. Neděla, O.; Slepička, P.; Švorčík, V. Surface Modification of Polymer Substrates for Biomedical Applications. Materials 2017, 10, 1115. [CrossRef]

29. Ghosh, S.; Abanteriba, S. Status of surface modification techniques for artificial hip implants. Sci. Technol. Adv. Mater. 2016, 17, 715-735. [CrossRef] [PubMed] 